\title{
Synthesis and Characterisation of a Biolubricant from Cameroon Palm Kernel Seed Oil Using a Locally Produced Base Catalyst from Plantain Peelings
}

\author{
Michael Bong Alang1, Maurice Kor Ndikontar'1, Yahaya Muhammad Sani², Peter T. Ndifon ${ }^{1 *}$ \\ ${ }^{1}$ Department of Inorganic Chemistry, University of Yaoundé I, Yaoundé, Cameroon \\ ${ }^{2}$ Department of Chemical Engineering, Ahmadu Bello University, Zaria, Nigeria \\ Email: *pndifon@yahoo.com
}

How to cite this paper: Alang, M.B., Ndikontar, M.K., Sani, Y.M. and Ndifon, P.T. (2018) Synthesis and Characterisation of a Biolubricant from Cameroon Palm Kernel Seed Oil Using a Locally Produced Base Catalyst from Plantain Peelings. Green and Sustainable Chemistry, 8, 275-287.

https://doi.org/10.4236/gsc.2018.83018

Received: June 8, 2018

Accepted: July 30, 2018

Published: August 2, 2018

Copyright $\odot 2018$ by authors and Scientific Research Publishing Inc. This work is licensed under the Creative Commons Attribution International License (CC BY 4.0).

http://creativecommons.org/licenses/by/4.0/

(c) (i) Open Access

\begin{abstract}
Biolubricant was synthesized from Cameroon palm kernel oil (PKO) by double transesterification, producing methyl esters in the first stage which were then transesterified with trimethylolpropane (TMP) to give the PKO biolubricant in the presence of a base catalyst obtained from plantain peelings (municipal waste). The yields from both catalysts were significantly similar ( $48 \%$ for the locally produced and $51 \%$ for the conventional) showing that the locally produced catalyst could be valorized. The synthesized biolubricant was characterized by measuring its physical and chemical properties. The specific gravity of 1.2 , ASTM color of 1.5 , cloud point of $0^{\circ} \mathrm{C}$, pour point of $-9^{\circ} \mathrm{C}$, viscosities at $40^{\circ} \mathrm{C}$ of $509.80 \mathrm{cSt}$ and at $100^{\circ} \mathrm{C}$ of $30.80 \mathrm{cSt}$, viscosity index of 120 , flash point greater than $210^{\circ} \mathrm{C}$ and a fire point greater than $220^{\circ} \mathrm{C}$ were obtained. This synthesized biolubricant was found to be comparable to commercial T-46 petroleum lubricant sample produced industrially from mineral sources. We have therefore used local materials to produce a biolubricant using a cheap base catalyst produced from municipal waste.
\end{abstract}

\section{Keywords}

Biolubricant, Transesterification, Palm Kernel Oil, Locally Produced Base Catalyst, Viscosity Index, Acid Value, Methyl Esters

\section{Introduction}

The world's crude oil reserves are rapidly depleting as a result of high consumption which exceeds the rate of natural formation of mineral deposits [1] and the 
world runs the risk of a severe energy crisis if rapid alternative energy solutions are not sought [2] [3]. These impending energy crises have provoked scientific and technological research on bio-based materials as alternative energy sources. The long term solutions to our energy needs depend on the development of renewable, biodegradable, and environmentally friendly industrial products such as biodiesel, biolubricants and other fuels that potentially substitute or subsidize conventional fuels and reduce the dependence on fossil fuels [4] [5] [6] [7] [8].

Lubricants minimize frictional resistance between surfaces in relative motion. They reduce mechanical wear and tear of machine components thereby increasing their life span and efficiency and also facilitate heat transfer, liquid sealing, contaminant suspension, and corrosion protection [1] [9]. There are two main types of lubricants namely, lubricants obtainable from fossil sources and those produced from vegetable oil sources. The demand for biodegradable and environmentally friendly bio-lubricants is on the increase, hence the need for scientific and technological research into the synthesis and production of such bio-lubricants from available vegetable oil sources. Similar work in this area includes the production of biolubricants from Nigerian Jatropha curcas seed oil [1]. Jatropha oil is not edible but highly unsaturated with attendant thermal instability. Consequently, biolubricant synthesis from Jatropha is a labor and capital intensive process.

We report here the synthesis and characterization of a bio-lubricant from Cameroonian palm kernel seed oil obtained from agricultural and industrial waste, emanating from palm oil processing industry in Cameroon. The oil is not edible and some is used as a raw material for the production of soaps and detergents.

\section{Materials and Methods}

\subsection{Materials}

Palm kernel seeds (Elaeis guineensis) were collected from the dumping site at an artisanal oil mill in Widikum (Cameroon) and mechanically cracked to separate the seeds from the hard shells. The seeds were sun-dried for 3 days to reduce the moisture content. The dried palm kernel seeds were used to extract palm kernel oil by mechanical press and solvent extraction. The palm kernel oil was and then characterized by physical and chemical methods. Reagent grade methanol, potassium hydroxide $(\mathrm{KOH})$, ethanol, ether, chloroform were used as purchased without further purification.

\subsection{Palm Kernel Oil Extraction}

Two kilograms $(2 \mathrm{~kg})$ of palm kernel seeds were crushed to a particle size of about $3 \mathrm{~mm}$ to allow solvent penetration and oil percolation and heated to about $80^{\circ} \mathrm{C}$ with open steam thereby humidifying the materials and raising the moisture content. The material was then flaked, and conveyed to the mechanical extracting system. For solvent extraction, $100 \mathrm{~g}$ of crushed palm kernel seeds was 
placed in the thimble-holder in a 2-L capacity Soxhlet extractor and diethyl ether $(300 \mathrm{~mL})$ added into the distillation flask [10]. The heating of the Soxhlet was regulated so that it made 4 siphons in 1 hour for a total of 7 hours for complete extraction to be achieved. The heating mantle was switched off and the extract allowed to cool down. The mixture was then gently heated to evaporate diethyl ether leaving palm kernel oil. The extracted PKO was characterized and the results are published [11].

\subsection{Biolubricant Synthesis by Double Transesterification of Palm Kernel Oil}

The PKO biolubricant was synthesized using the double transesterification method [1]. The first step produced intermediate products of methyl esters of fatty acids which were used in the second step to produce the biolubricant in the presence of trimethylolpropane (TMP). The two processes were carried out as described below.

\subsubsection{Production of $\mathrm{KOH}$ Using Plantain Peelings}

An alternative source of the base catalyst was explored primarily for the sake of economics of production. The catalyst precursor was derived from plantain fruit (Musa paradisiaca) peelings, an urban waste product. Three kilograms of plantains peelings were collected from an urban waste dump in the Bamenda (Cameroon) municipality, washed with water to remove soil, debris and other impurities and sun-dried for one week to reduce the moisture content and to render the peelings easily combustible [12] [13]. The plantain peelings were then burnt in an air-rich metallic container; the ash was collected and stored in a labeled polythene bag. The residual ash is predominantly potassium oxide $\left(\mathrm{K}_{2} \mathrm{O}\right)$ which dissolves in water to give $\mathrm{KOH}$ solution. The base catalyst $(\mathrm{KOH})$ was extracted from the ash following a modified procedure by Enontiemonria et al. [13]. In this extraction, $30 \mathrm{~g}$ of dry ash was dissolved in $300 \mathrm{~mL}$ of mineral free water using $500-\mathrm{mL}$ beakers. The beaker and its content were placed on a hot plate magnetic stirrer and kept at $50^{\circ} \mathrm{C}$ for 4 hours. The resultant solution was then filtered using filter paper and stored. The filtrate was collected in a stainless steel container, verified with litmus paper for $\mathrm{pH}$ value and evaporated to dryness. The dried residue was weighed and stored in a plastic container. The percentage of $\mathrm{KOH}$ recovered was calculated using Equation (1).

$$
\% \mathrm{KOH}=\frac{\text { mass of } \mathrm{KOH} \text { obtained }}{\text { mass of ash taken }} \times 100
$$

\subsubsection{Synthesis of Methyl Ester using Conventional $\mathrm{KOH}$}

Purified PKO $(100 \mathrm{~mL})$ was transferred into a heating pan and warmed to $50^{\circ} \mathrm{C}$. Methanol $(24 \mathrm{~mL})$ was transferred into a beaker and potassium hydroxide $(\mathrm{KOH})(0.9234 \mathrm{~g})$ added and stirred magnetically until all the $\mathrm{KOH}$ was completely dissolved. The warm PKO was transferred into the reaction vessel (500-mL round bottom distillation flask) and the catalyst (1\% mass of PKO) was 
added. The contents of the reaction vessel were swirled vigorously for five minutes. The reaction mixture was then heated under reflux in a water bath at $70^{\circ} \mathrm{C}$ for 45 minutes during which the transesterification reaction took place. The content of the reaction vessel was transferred into a separatory funnel and visible separation of methyl esters as the supernatant liquid was observed after $15 \mathrm{mi}$ nutes. Overnight, the reaction mixture separated into the upper amber colored methyl esters layer and the lower impure glycerol layer (see Figure 1). The products were separated by allowing each fraction to flow into separate labeled measuring cylinders. The methyl esters were purified using the modified procedure by Aladetuyi et al. [14] and the yield of methyl ester calculated using Equation (2) [14] [15] [16].

$$
\text { yield of methyl esters }=\frac{V_{P}}{V_{S}} \times 100
$$

where $V_{p}$ is the volume of product and $V_{s}$ the volume of sample oil used for the synthesis.

\subsubsection{Synthesis of Biolubricant}

The synthesis of biolubricant from palm kernel oil methyl esters (PKOME) by transesterification with trimethylolpropane (TMP) is depicted by the following stoichiometric equation (Scheme 1).

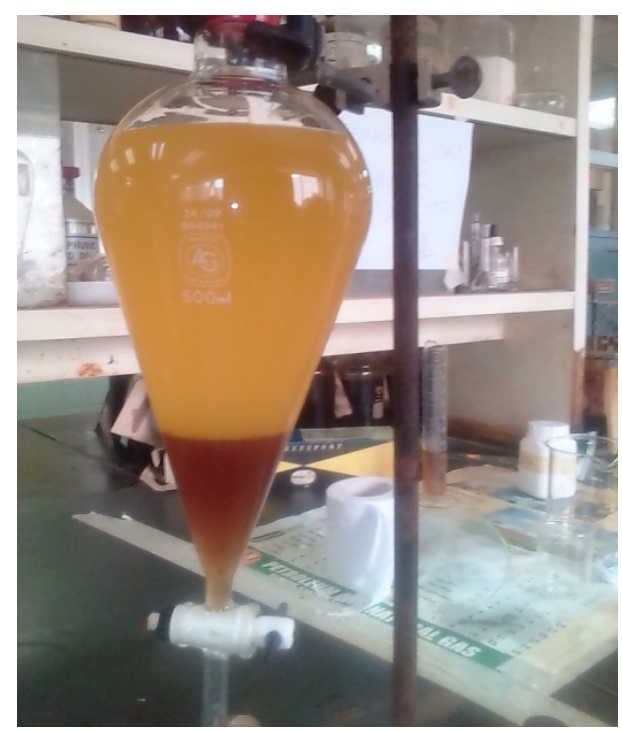

Figure 1. Methyl esters synthesized (Upper layer).<smiles>CCC(CO)(CO)CO</smiles>

Trimethylolpropane-TMP

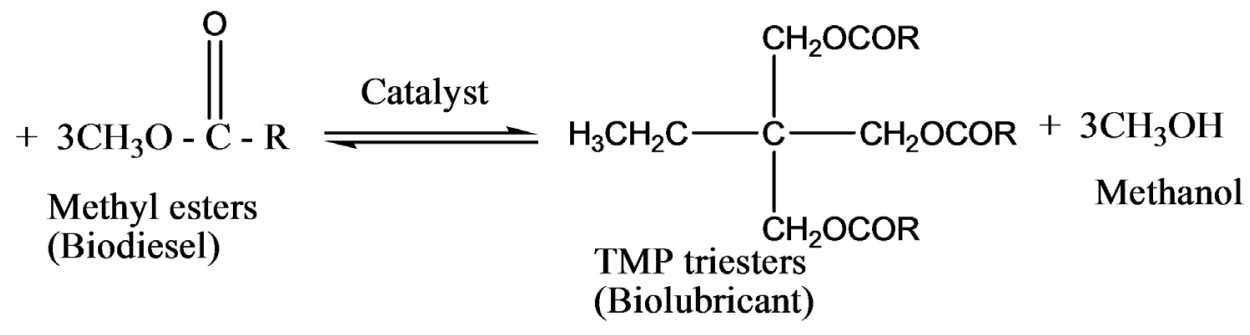

Scheme 1. Production of TMP Biolubricant. 
The previously prepared palm kernel oil methyl esters (PKOME) $(100 \mathrm{~mL})$ in a $500-\mathrm{mL}$ reaction vessel was heated in a water bath to $70^{\circ} \mathrm{C}$ and $0.9 \mathrm{~g}$ of $\mathrm{KOH}$ base catalyst solution was added. After 10 minutes, $20 \mathrm{~g}$ of TMP crystals were added to the reaction vessel and the reaction allowed to proceed for 4 hours at $100^{\circ} \mathrm{C}$ under reflux. The reaction mixture allowed to cool to room temperature. The mixture was transferred into a separatory funnel and the TMP triester (biolubricant) was collected as the bottom viscous layer. The biolubricant yield was calculated using Equation (3) [17].

$$
\% \text { yield }=\frac{V_{P}}{V_{S}} \times 100
$$

where $V_{p}$ is the volume of product and $V_{s}$ the volume of sample taken.

\subsubsection{Biolubricant Synthesis Using KOH from Plantain Peelings}

Biolubricant was synthesized using locally made base-catalyst. $100-\mathrm{mL}$ of palm kernel oil methyl esters (PKOME) was measured into a $500-\mathrm{mL}$ reaction vessel. $4.62 \mathrm{~g}$ of locally made $\mathrm{KOH}$ corresponding to $5 \%$ weight of PKOME was dissolved in $10 \mathrm{~mL}$ of methanol with the aid of a magnetic stirrer. The catalyst solution was added to the 500-mL reaction vessel and the mixture swirled for five minutes followed by the addition of $20 \mathrm{~g}$ of TMP to the reaction mixture which was then maintained in a water bath at $100^{\circ} \mathrm{C}$ for 4 hours. The reaction mixture was allowed to cool to room temperature. The mixture was transferred into a separatory funnel for the biolubricant to decant as the bottom viscous layer which was collected directly into a measuring cylinder. The supernatant layer was recycled by transferring it back to the reaction vessel and adding more catalyst and TMP and repeating the heating process for four hours. The lubricant formed in the recycled batch was separated and the total yield computed.

\subsection{Characterization of PKO Biolubricant}

The biolubricant was analyzed for its physical and chemical properties [18] [19]. The specific gravity was determined using the density bottle method while the rest of the properties were determined using standard analytical methods as shown in Table 1 [1] [20].

A sample of commercial petroleum lubricant was obtained from the Quality Control Laboratory of the Kaduna Refinery and Petrochemical Company (KRPC) and subjected to similar analyses to compare with synthesized biolubricant from palm kernel oil. The chemical compositions of both lubricants were investigated using the Gas Chromatography-Mass Spectrometry QP2010 plus with helium gas as the carrier medium.

\section{Results and Discussions}

The physico-chemical properties of the products are shown in Table 2. Bio-based lubricants derived from vegetable oils are biodegradable and have lower eco-toxicity compared to petroleum lubricants [21]. However, several studies 
Table 1. Characterization of PKO Biolubricants by Standard Analytical Methods [20].

\begin{tabular}{cc}
\hline Parameter & Analytical Method \\
\hline ASTM color & ASTM D1500 \\
Viscosity at $40^{\circ} \mathrm{C}$ & ASTM D445 \\
Viscosity at $100^{\circ} \mathrm{C}$ & ASTM D445 \\
Viscosity index & ASTM D 2270 \\
Cloud point & ASTM D2500 \\
Pour point & ASTM D97 \\
Flash point & ASTM D93 \\
Fire point & ASTM D93 \\
IR Spectroscopy & FTIR \\
\hline
\end{tabular}

Table 2. Characteristics of PKO, Biolubricants and Petroleum Lubricant.

\begin{tabular}{ccccc}
\hline Property & PKO [11] & $\begin{array}{c}\text { Biolubricant using } \\
\text { locally made catalyst }\end{array}$ & $\begin{array}{c}\text { Biolubricant using } \\
\text { conventional catalyst }\end{array}$ & Petrolubricant \\
\hline S.G (g/mL) & 0.923 & 1.22 & 1.20 & 0.848 \\
Color & $<2.5$ & $<2.0$ & 1.50 & $<0.5$ \\
Viscosity @ $40^{\circ} \mathrm{C}(\mathrm{cSt})$ & 26.03 & 480.63 & 509.80 & 46.476 \\
Viscos. @ 100 ${ }^{\circ} \mathrm{C}(\mathrm{cSt})$ & 5.934 & 20.54 & 30.80 & 6.940 \\
Viscosity Index & 185 & 110 & 90 & 105 \\
Cloud Point $\left({ }^{\circ} \mathrm{C}\right)$ & 29 & 0 & 0 & -5 \\
Pour Point $\left({ }^{\circ} \mathrm{C}\right)$ & 20 & -8 & -9 & -20 \\
Flash Point $\left({ }^{\circ} \mathrm{C}\right)$ & 200 & $>210$ & $>210$ & 220 \\
Fire Point $\left({ }^{\circ} \mathrm{C}\right)$ & 220 & $>220$ & $>220$ & 231 \\
\hline
\end{tabular}

have shown that vegetable oils have limitations as lubricants without structural modification [21] [22] [23]. Such limitations include thermal, oxidative and hydrolytic instability and inadequate low temperature fluidity due to high pour points [21] [24]. These limitations are due to the presence of the glycerol moiety which is a major component in vegetable oil. The susceptibility of this molecule to high temperature destruction is due to the presence of a $\beta$-hydrogen atom on the second carbon atom of the glycerol molecule [22] [23] which is more acidic and unstable. Most of these shortcomings can be minimized by chemical modification through transesterification of vegetable oil with polyhydric alcohols [21].

The PKO biolubricant synthetic method (double transesterification) causes the elimination of the $\beta$-hydrogen atom from the vegetable oil structure and provides an ester with high degree of oxidative and thermal stability which is seldom found in vegetable oils [25]. In the double transesterification procedure, the glycerol molecule bearing the unstable hydrogen in vegetable oil is substituted by a more stable TMP. The first stage of transesterification gets rid of the glycerol molecule while the second stage puts a more potent molecule (TMP) in 
the place of glycerol thus giving trimethylolpropane triester (TMPTE) which has superior properties and performance.

The yield of biolubricant calculated from conventional base catalyst was 51.0\% while that from locally produced base catalyst was $48.6 \%$. This implies that the locally produced catalyst is almost as effective as the conventional, imported catalyst. This minimizes production cost, thus reducing the cost of the biolubricant and enhancing affordability and valorizing municipal waste through transformation into a useful product for the conversion of industrial wastes (palm kernel seeds) into biolubricant. This is in conformity with the observation that energy conversion is sustainable and cheaper when it is derived from waste and renewable biomass [26].

In order to evaluate the propinquity of the synthesized biolubricant to the conventional lubricant, a petroleum lubricant sample was also analyzed using similar parameters as those determined for the biolubricant. The results in Table 2 show that biolubricant is heavier and more viscous than the petroleum lubricant. These properties are responsible for the higher mechanical (load) and thermal resistance of the biolubricant over the mineral lubricant. The viscosity indices and cold flow properties are generally similar indicating that the biolubricant can be blended with the petroleum counterpart to complement one another and thus produce a hybrid and more synergistic product. The propensity to fire hazards of products is determined by the flash and fire points. The flash and fire points of the biolubricant are slightly greater than those of the vegetable oil PKO showing the enhanced thermal resistance of the product of transesterification with TMP. The flash and fire points of the biolubricant are not too different from petroleum lubricant implying its greater thermal stability. The biolubricant may therefore require some antifoaming additives to complement its properties as it exhibited slight foaming at higher temperatures.

\subsection{Variation of Specific Gravities (SG) of Products}

From the results obtained, the specific gravity of PKO biolubricant catalyzed by locally produced base catalyst, $1.22 \mathrm{~g} / \mathrm{mL}$ is similar that of the PKO biolubricant catalyzed by conventional base catalyst, $1.20 \mathrm{~g} / \mathrm{mL}$. Both SGs are higher than that of precursor PKO, $0.923 \mathrm{~g} / \mathrm{mL}$; with the petroleum lubricant having the lowest specific gravity value at $0.848 \mathrm{~g} / \mathrm{mL}$. The specific gravity value is lower for palm kernel seed oil than for biolubricant due to an increase in molecular complexity brought in by the trimethylolpropane (TMP) backbone. The specific gravity value for the biolubricant is higher than that of the petrolubricant due to a change in chemical structure of constituent molecules which are predominantly saturated aliphatic and few aromatic hydrocarbons. The specific gravity of the biolubricant catalyzed by locally produced base catalyst is higher probably due to slightly higher impurity level as suggested by the ASTM color values. The change in specific gravity leads to a corresponding change in the mass of the products. The greater the specific gravity, the heavier and more viscous the oil is, and such 
a lubricant does not easily thin out at higher temperature and can withstand greater loads. The specific gravity is also an indicator of product adulteration. The SG of the biolubricant for PKO, biolubricant and petrolubricant determines the compatibility of the products with either the heavy or light duty engines which is the ability of a sample to mix with other liquids [27]. Substances with smaller SG $(<1)$ can float in water while those with SG greater than one sink in water. The persistence of biolubricant on applied surfaces and joints would be longer due to higher specific gravity and consequently, higher viscosity.

\subsection{Kinematic Viscosities of Products at $40^{\circ} \mathrm{C}$ and at $100^{\circ} \mathrm{C}$}

The viscosities of biolubricants were $509.80 \mathrm{cSt}$ at $40^{\circ} \mathrm{C}$ and $30.80 \mathrm{cSt}$ at $100^{\circ} \mathrm{C}$ respectively using conventional base catalyst $(\mathrm{KOH})$. The values for the biolubricant catalyzed by base catalyst produced from plantain peelings were comparatively high as well. These values for PKO biolubricant are greater than those of biolubricant from Jatropha oil which were reported as $55.17 \mathrm{cSt}$ at $40^{\circ} \mathrm{C}$ and $10.96 \mathrm{cSt}$ at $100^{\circ} \mathrm{C}$ respectively [1]. The values for PKO biolubricant are higher than those of petroleum lubricants which were measured as $46.476 \mathrm{cSt}$ at $40^{\circ} \mathrm{C}$ and $6.9404 \mathrm{cSt}$ at $100^{\circ} \mathrm{C}$. This is indicative that PKO biolubricant possesses greater thermal stability and can withstand greater mechanical stress than petroleum lubricants. Viscosity is a measure of the ease of flow of a fluid. It is determined by measuring the amount of time taken for a given measure of fluid to flow through an orifice of a specified size [28]. The viscosities of products at $40^{\circ} \mathrm{C}$ are generally much greater than the viscosities at $100^{\circ} \mathrm{C}$ due to the fact that intermolecular forces resisting flow in liquids such as hydrogen bonds and van der Waals forces are largely broken down at higher temperatures.

\subsection{Viscosity Index Variation}

The viscosity index values for the PKO biolubricants catalyzed by conventional and unconventional catalysts and petro-lubricant are 90, 110 and 105 respectively. The values are moderately high and very close to that of the petroleum lubricant. Hence chemical synthesis has produced a lubricant from organic and renewable sources with similar properties to lubricants of mineral origin more especially with the added advantage of biodegradability. Most liquids tend to thin out when temperatures increase and thicken when temperatures decrease. The property of a liquid to resist changes in viscosity when temperature increases or decreases is called viscosity index. Higher values of viscosity index are desirable because such a lubricant greatly resists changes in viscosity when temperature changes. The viscosity index of PKO is high (185) in addition to its high flash point of $200^{\circ} \mathrm{C}$. This implies, pure palm kernel oil itself is a potent lubricant with some limitations when used at high temperatures [27]. The high temperature limitations stem from the glycerol backbone in triglycerides which are significant chemical components of vegetable oils. This glycerol component is rea-

dily destructible at high temperatures due to the presence of hydrogen atoms in 
the beta position relative to the hydroxyl group in the glycerol molecule [21].

\subsection{Cold Flow Properties}

The cloud point of oil refers to the temperature at which wax first become visible as the temperature is lowered while the pour point is the temperature at which the oil solidifies enough to resist flow [29]. The cloud point was reduced from $29^{\circ} \mathrm{C}$ for PKO to $0^{\circ} \mathrm{C}$ for biolubricants after double transesterification and the process similarly reduced the pour point of palm kernel oil from $20^{\circ} \mathrm{C}$ to $0^{\circ} \mathrm{C}$ in biolubricants. The clouds points of the biolubricants are $0^{\circ} \mathrm{C}$ each while the pour points are -8 and $-9^{\circ} \mathrm{C}$. The cloud point of the petroleum lubricant is $-5^{\circ} \mathrm{C}$ while the pour point is $-20^{\circ} \mathrm{C}$. These results suggest that the cold flow properties of the biolubricants and petro-lubricant are adequate to permit their use at extreme temperatures. For the biolubricant, the thermal resistance of the product is enhanced as the thermally fragile glycerol in the palm kernel oil triglycerides is replaced by the trimethylolpropane backbone which is thermally stable. Hence the biolubricant synthesized from palm kernel oil has better properties in terms of thermal stability and cold flow, compared to neat palm kernel oil lubricant.

\subsection{Flash Points of Products}

The flash point of a fuel refers to the temperature at which the fuel can ignite when exposed to a heat source. The flash point is of relevance when safe handling, storage and transportation are concerned [30] [31]. The flash points of PKO and PKO biolubricant were $200^{\circ} \mathrm{C}$ and $210^{\circ} \mathrm{C}$ respectively. These products are therefore classified as non-hazardous products because of their high flash points. The flash point of a lubricant refers to the temperature at which some vapor is emitted from the substance to momentarily ignite a flame while the fire point is the temperature at which enough vapor is emitted from the substance undergoing a heating program to sustain a flame [32]. The flash and fire points are the properties that must be considered in assessing the overall flammability hazard of a biolubricant and related materials. The neat flash point and fire points of PKO biolubricant were not obtained with certainty because the product foamed at $210^{\circ} \mathrm{C}$. The flash and fire points of the petroleum lubricant were 220 and $231^{\circ} \mathrm{C}$ respectively. The approximate results are in the range of those reported by Mohammed et al. [23] which gave the flash point of Neem biolubricant as $262^{\circ} \mathrm{C}$ and that of Jatropha biolubricant as $274^{\circ} \mathrm{C}$ [1]. The PKO biolubricant thus exhibited some foaming characteristics. Foaming characteristics in an industrial lubricant is undesirable as it may interfere with the overall system performance and may lead to some mechanical damage. Consequently, antifoaming agents may be used to minimize the foaming propensity of the PKO biolubricants synthesized.

\subsection{IR Analysis of Biolubricant}

Vibrational frequencies of organic molecules are widely used in qualitative and 


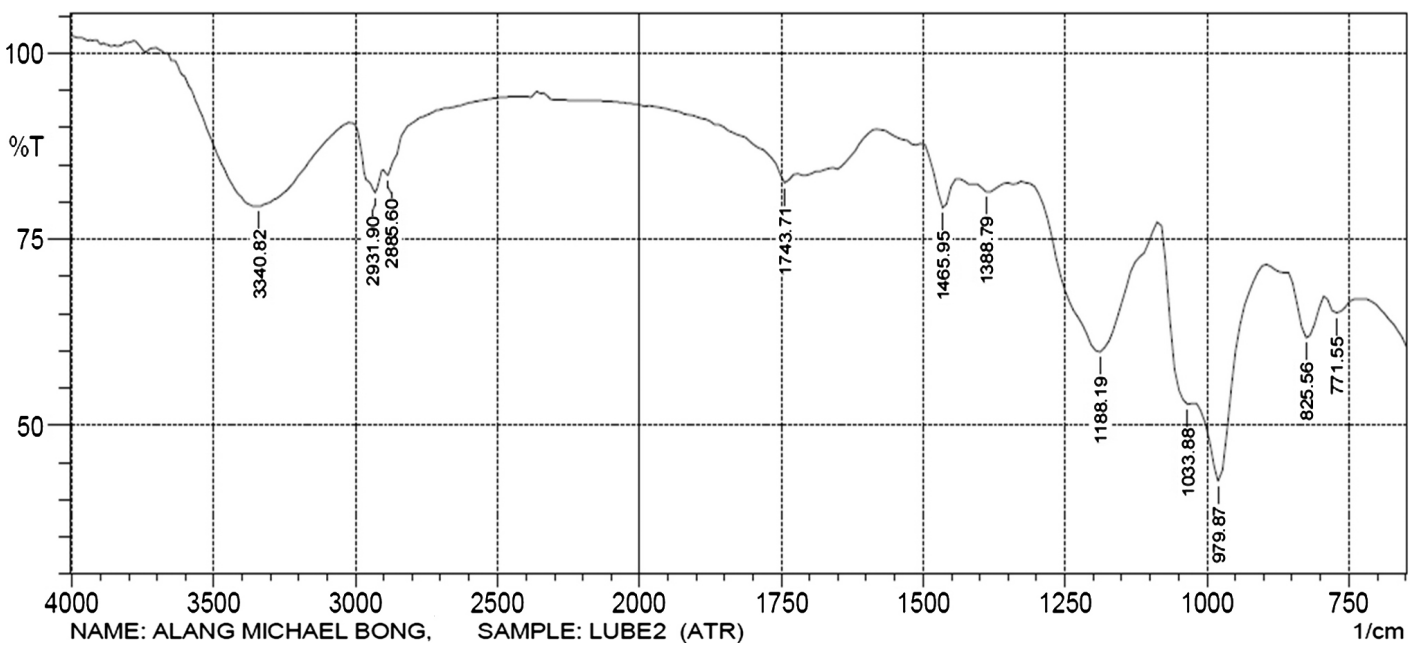

Figure 2. IR Spectrum of PKO Biolubricant.

quantitative analysis to identify different absorption chromorphores. The vibrational frequencies are sub-classified into group frequencies characteristic of groups of atoms or functional groups and fingerprint frequencies characteristic of specific molecules. The synthesized biolubricant was analyzed by FTIR to ascertain that the transesterification reaction between methyl esters and trimethylolpropane (TMP) did effectively take place. The IR spectra of the PKO biolubricant are elucidated by Figure 2 .

From the spectrum, the prime peak of relevance occurs at $1743.7 \mathrm{~cm}^{-1}$ which falls in the range of carbonyl $(\mathrm{C}=\mathrm{O})$ absorption for esters [33]. The absorption peaks at 2931 and $2886 \mathrm{~cm}^{-1}$ fall in the absorption range for $\mathrm{C}-\mathrm{H}$ stretching in the hydrocarbon component of the biolubricant. The broad absorption peak at $3340 \mathrm{~cm}^{-1}$ suggests the presence of $\mathrm{O}-\mathrm{H}$ groups from some TMP impurity molecules.

\section{Conclusions}

A biolubricant with good lubricant properties for higher temperature applications has been produced from Cameroon palm kernel oil. A new base catalyst was produced from municipal wastes (plantain peelings), whose performance was very close to that of conventional base catalyst $(\mathrm{KOH})$ used in this work. We have therefore used local materials to produce a biolubricant using cheap base catalyst.

However, further research is required to improve on the yield of the biolubricant, optimize the production of the base catalyst from plantain peelings and improve the purity level. Also the performance of the synthesized biolubricant needs to be studied in a sample engine to evaluate its suitability in various engines.

\section{Conflicts of Interest}

The authors declare no conflicts of interest regarding the publication of this paper. 


\section{References}

[1] Bilal, S1, Mohammed-Dabo, I., Nuhu, M., Kasim, S., Almustapha, I. and Yamusa, Y. A. (2013) Production of Biolubricant from Jatropha curcas Seed Oil. Journal of Chemical Engineering and Material Science, 4, 72-79.

[2] Alamu, O.J., Waheed, M.A. and Jekayinfa, S.O. (2007) Biodiesel Production from Nigerian Palm Kernel Oil: Effect of KOH Concentration on Yield. Energy for Sus tainable Development, 11, 77-82.

[3] Baroi, C., Yanful, E.K. and Bergougnou, M.A. (2009) Biodiesel Production from Jatropha curcas Oil Using Potassium Carbonate as an Unsupported Catalyst. International Journal of Chemical Reactor Engineering, 7, Article A72.

[4] Sahoo, P.K., Das, L.M., Babu, M.K.G. and Naik, S.N. (2007) Biodiesel Development from High Acid Value Polanga Seed Oil and Performance Evaluation in CI Engine. Fuels, 86, 448-454. https://doi.org/10.1016/j.fuel.2006.07.025

[5] Basha, S.A., Raja Gopal, K. and Jebaraj, S. (2009) A Review on Biodiesel Production, Combustion, Emissions and Performance. Renewable and Sustainable Energy Reviews, 13, 1628-1634. https://doi.org/10.1016/j.rser.2008.09.031

[6] Demirbas, A. (2009) Biofuels Securing the Planet's Future Energy Needs. Energy Conversion and Management, 50, 2239-2249. https://doi.org/10.1016/j.enconman.2009.05.010

[7] Refaat, A.A. (2010) Different Techniques for the Production of Biodiesel from Waste Vegetable Oil. International Journal of Environmental Science \& Technology, 7, 183-213. https://doi.org/10.1007/BF03326130

[8] Yang, C.Y., Li, Z.F.B. and Long, Y.F. (2012) Review and Prospects of Jatropha Biodiesel Industry in China. Renewable and Sustainable Energy Reviews, 16, 2178-2190. https://doi.org/10.1016/j.rser.2012.01.043

[9] Jumat, S., Nadia, S. and Emad, Y. (2010) Biolubricants: Raw Materials, Chemical Modifications and Environmental Benefits. European Journal of Lipid Science and Technology, 112, 519-530.

[10] Luque de Castro, M.D. and Garcia Ayuso, L.E. (2000) Soxhlet Extraction. Environmental applications. University of Cordoba, Cordoba, Spain, 2701-2709.

[11] Bong, A.M., Kor, N.M., Ndifon, P.T. and Sani, Y.M. (2018) Synthesis and Characterisation of Biodiesel from Cameroon Palm Kernel Seed Oil. Asian Journal of Biotechnology and Bioresource Technology, 3, 1-17. https://doi.org/10.9734/AJB2T/2018/40200

[12] Taiwo, A.A., Oluwadare, I., Shobo, A.O. and Amolegbe, S.A. (2008) Extraction and Potential Application of Caustic Potash from Kolanut Husk, Ugwu Pod Husk and Plantain Peels. Scientific Research and Essay, 3, 515-517.

[13] Enontiemonria, E.V., Abiodun, O.J. and Eric, K.E. (2016) Extraction and Use of Potassium Hydroxide from Ripe Plantain Peels Ash for Biodiesel Production. Journal of Biobased Materials and Bioenergy, 10, 1-9. https://doi.org/10.1166/jbmb.2016.1567

[14] Aladetuyi, A., Olatunji, G.A., Ogunniyi, D.S. and Odetoye, T.E. (2014) Production and Characterization of Biodiesel Using Palm Kernel Oil, Fresh and Recovered from Spent Bleaching Earth. Biofuel Research Journal, 4, 134-138. https://doi.org/10.18331/BRJ2015.1.4.6

[15] Ribeiro, L.M., Silva, A., Silva, M.C. and Almeida, R.M.R.G (2014) A Study on Ethanolysis and Methanolysis of Coconut Oil for Enzymatically Catalyzed Production of Biodiesel. Journal of Sustainable Bioenergy Systems, 4, 215-224. 
https://doi.org/10.4236/jsbs.2014.44020

[16] Viele, E.L., Chukwuma, F.O. and Uyigue, L. (2014) Production and Characterization of Biodiesel from Crude Palm Kernel Oil and Bio-Ethanol Using Potash from Ash of Empty Oil Palm Bunch Residue as Catalyst. International Journal of Application or Innovation in Engineering \& Management, 3, 11-22.

[17] Ribeiro, L.M.O., Silva, A.E., Silva, M.C.S. and Almeida, R.M.R.G. (2014) A Study on Ethanolysis and Methanolysis of Coconut Oil for Enzymatically Catalyzed Production of Biodiesel. Journal of Sustainable Bioenergy Systems, 4, 215-224. https://doi.org/10.4236/jsbs.2014.44020

[18] Dormo, N., Belafi-Bako, K., Bartha, L., Ehrenstein, U. and Gubicza, L. (2004) Manufacture of an Environmental-Safe Biolubricant from Fusel Oil by Enzymatic Esterification in Solvent Free System. Biochemical Engineering Journal, 21, 229-234. https://doi.org/10.1016/j.bej.2004.06.011

[19] Chandu, S.M., Subhalaxmi, P. and Naik, S.N. (2010) Production of Biolubricants from Castor Oil in Sub and Supercritical Carbon Dioxide Mediated Enzymatic Reactions. Centre for Rural Development and Technology, Indian Institute of Technology, New Delhi, 1-4.

[20] Nadkarni Kishore, R.A. (2007) Guide to ASTM Test Methods for the Analysis of Petroleum Products and Lubricants. 2nd Edition, ASTM International, West Conshohocken, 1-76. https://doi.org/10.1520/MNL44-2ND-EB

[21] Yunus, R. (2015) Biobased Lubricants; Harnessing the Richness of Agriculture Resources. University Putra Malaysia Press, 15-50. http://www.penerbit.upm.edu.my

[22] Gunam Resul, M.F., Mohd. Ghazi, T.I., Muhammad Syam, A. and Idris, A. (2001) Synthesis of Biodegradable Lubricant from Jatropha Oil with High Content of Free Fatty Acids. Selangor Darul Ehsan, Serdang, 1-7.

[23] Aji, M.M., Kyari, S.A. and Zoaka, G. (2015) Comparative Studies between Bio Lubricants from Jatropha Oil, Neem Oil and Mineral Lubricant (Engen Super 20w/50). Applied Research Journal, 1, 252-257.

[24] Sharma, B.K., Adhvaryu, A., Liu, Z. and Erhan, S.Z. (2006) Chemical Modification of Vegetable Oils for Lubricant Applications. JAOCS, 83, 129. https://doi.org/10.1007/s11746-006-1185-Z

[25] Wagner, H., Luther, R. and Mang, T. (2001) Lubricant Base Fluids Based on Renewable Raw Materials: Their Catalytic Manufacture and Modification. Applied Catalysis A, 221, 429. https://doi.org/10.1016/S0926-860X(01)00891-2

[26] Dara, S.S. (2008) A Textbook of Engineering Chemistry. S. Chand and Company Limited, New Delhi, 633-643.

[27] Musa, J.J. (2009) Evaluation of the Lubricating Properties of Palm Kernel Oil. Leonardo Electronic Journal of Practices and Technologies, 14, 107-114.

[28] Alamu, O.J., Opeoluwa, D. and Adedoyin, M.S. (2010) Production and Testing of Coconut Oil Biodiesel Fuel and Its Blend. Leonardo Journal of Sciences, 16, 95-104.

[29] Bello, E.I., Oguntuase, B., Osasona, A. and Mohammed, T.I. (2015) Characterization and Engine Testing of Palm Kernel Oil Biodiesel. European Journal of Engineering and Technology, 3, 11-21.

[30] Raja, S.A., Smart, D.S.R. and Lee, C.L.R. (2011) Biodiesel Production from Jatropha Oil and Its Characterization. Research Journal of Chemical Sciences, 1, 81-87.

[31] Musa, N.A., Teran, G.M. and Yaman, S.A. (2016) Characterization of Coconut Oil and Its Biodiesel. Journal of Scientific Research \& Reports, 9, 1-6.

https://doi.org/10.9734/JSRR/2016/22293 
[32] Garki, I.D. and Aliyu, M.A. (2017) Fuels and Gas Laboratory Manual. Test Procedures Petroleum Products Quality Control (PPQC) Department. Kaduna Refinery and Petrochemical Company (KRPC) - Kaduna State, 1-64.

[33] Mayo, D.W., Miller, F.A. and Hannah, R.W. (2003) Spectra of Carbonyl Compounds of All Kinds (Factors Affecting Carbonyl Group Frequencies); Course Notes on the Interpretation of Infrared and Raman Spectra. Chapter 7, John Wiley \& Sons, Inc., Hoboken, 179-204. 